А. А. Виноградов, А. Н. Плеханов, А. И. Товаршинов, В. А. Виноградов, И. А. Ольховский, Л. В. Борбоев. Опыт хирургического лечения ущемленных паховых и бедренных грыж

Научная статья

УДК 616-007.43

DOI: $10.18101 / 2306-1995-2021-2-9-15$

\title{
ОПЫТ ХИРУРГИЧЕСКОГО ЛЕЧЕНИЯ УЩЕМЛЕННЫХ ПАХОВЫХ И БЕДРЕННЫХ ГРЫЖ
}

\section{(C) Виноградов Алексей Анатольевич}

врач-хирург,

Клиническая больница «РЖД-Медицина»

Россия, 670001, г. Улан-Удэ, ул. Комсомольская, 16

winogradow.a@yandex.ru

\section{(C) Плеханов Александр Николаевич}

доктор медицинских наук, профессор, заведующий кафедрой факультетской хирургии, Бурятский государственный университет имени Доржи Банзарова

Россия, 670002, г. Улан-Удэ, ул. Октябрьская, 36а

главный врач,

Клиническая больница «РЖД-Медицина»

Россия, 670001, г. Улан-Удэ, ул. Комсомольская, 16

plehanov.a@mail.ru

\section{(C) Товаршинов Александр Искрович}

кандидат медицинских наук, доцент кафедры факультетской хирургии,

Бурятский государственный университет имени Доржи Банзарова

Россия, 670002, г. Улан-Удэ, ул. Октябрьская, 36а

tovarschinov.a@mail.ru

\section{(C) Виноградов Владимир Алексеевич}

студент 2-го курса,

Бурятский государственный университет имени Доржи Банзарова

Россия, 670002, г. Улан-Удэ, ул. Октябрьская, 36а

kvendingo.mail.ru@gmail.com

\section{() Ольховский Игорь Александрович}

старший преподаватель,

Бурятский государственный университет имени Доржи Банзарова

Россия, 670002, г. Улан-Удэ, ул. Октябрьская, 36а

winogradow.a@yandex.ru

\section{(C) Борбоев Леонид Владимирович}

старший преподаватель,

Бурятский государственный университет имени Доржи Банзарова

Россия, 670002, г. Улан-Удэ, ул. Октябрьская, 36а

borboev@mail.ru

Аннотация. В статье оценивается опыт хирургического лечения ущемленных паховых и бедренных грыж в хирургическом отделении ЧУЗ «КБ «РЖД-Медицина», г. Улан-Удэ. Вентральные грыжи являются одной из наиболее распространенных патологий в хирургии во всем мире, при этом результаты лечения пациентов остаются 
неудовлетворительными, отмечается высокий уровень осложнений, послеоперационной летальности.

Такая ситуация связана с поздней обращаемостью пациентов за медицинской помощью, несвоевременным оперативным вмешательством, пожилым и старческим возрастом пациентов с выраженной сопутствующей патологией и стертой клинической картиной. Существуют проблемы дифференциальной диагностики, а также тактические ошибки при выборе доступа, определении объема оперативного вмешательства и способа пластики.

Метод операций по Nyhus является патогенетически обоснованным в лечении паховых и бедренных грыж, универсальным, позволяя четко дифференцировать анатомические образования пахово-бедренной области, производить ревизию брюшной полости, выполнять резекцию ущемленных некротизированных органов, обходясь при этом без дополнительной срединной лапаротомии, эндотрахеального наркоза, что важно для пациентов преклонного возраста с сопутствующей тяжелой патологией.

Ключевые слова: грыжа, ущемление, метод Нигуса, хирургическое лечение, паховые и бедренные грыжи.

\section{Для цитирования}

Опыт хирургического лечения ущемленных паховых и бедренных грыж / А. А. Виноградов, А. Н. Плеханов, А. И. Товаршинов и др. // Вестник Бурятского государственного университета. Медицина и фармация. 2021. № 2. С. 9-15.

Вентральные грыжи являются одной из наиболее распространенных патологий в хирургии, в популяции они встречаются у 3-4\% населения. Среди всех грыж паховые занимают 70\%, бедренные - 10\%. Паховые грыжи у мужчин бывают в 6 раз чаще, чем у женщин, бедренные грыжи встречаются значительно чаще у женщин. Ущемление паховых грыж возникает в $60 \%$ всех ущемлений грыж, бедренных - в 25\% [1-4]. В структуре экстренных хирургических заболеваний ущемленные грыжи находятся на 4-5-м месте после острого панкреатита, острого аппендицита, острого холецистита. В России соотношение плановых и экстренных операций при грыжах остается на уровне 4:1-5:1, а в Европе и США показатель составляет 15:1. Результаты лечения пациентов с ущемленными паховыми грыжами до сих пор остаются неудовлетворительными, с неприемлемо высоким уровнем осложнений, а также послеоперационной летальностию, которая по некоторым данным может достигать $18 \%$.

Неудовлетворительные результаты лечения связаны с поздней обращаемостью пациентов за медицинской помощью, поздней диагностикой и несвоевременным оперативным вмешательством, что, в свою очередь, обусловлено поздней госпитализацией пациентов, бо́льшая часть которых пожилого и старческого возраста с выраженной сопутствующей патологией и стертой клинической картиной. Существуют проблемы дифференциальной диагностики, а также тактические ошибки при выборе доступа, определении объема оперативного вмешательства и способа пластики $[1-4,10]$.

Известно более 300 способов хирургического лечения паховых и бедренных грыж [1, 3-5]. В хирургическом отделении ЧУЗ «КБ «РЖД Медицина» г. УланУдэ в течение последних 30 лет наряду с традиционными операциями из переднего доступа, в основном способом Бассини, а в последние 15 лет и способом Лихтенштейна, применяется способ Nyhus. 
А. А. Виноградов, А. Н. Плеханов, А. И. Товаршинов, В. А. Виноградов, И. А. Ольховский, Л. В. Борбоев. Опыт хирургического лечения ущемленных паховых и бедренных грыж

Сущность методики заключается в следующем. Доступ по Nyhus: разрез кожи и подкожной клетчатки около $10 \mathrm{~cm}$ от передней верхней подвздошной ости до средней линии живота на 2,5-3 см выше лонного сочленения. Вскрываются передняя стенка влагалища прямой мышцы, апоневроз наружной косой мышцы, перимизий внутренней косой мышцы, сама мышца вместе с поперечной мышцей живота расслаивается вдоль волокон. Рассекается поперечная фасция вдоль разреза. Открывается пространство между брюшиной и задней стенкой пахового канала, представленной поперечной фасцией с «задней» стороны.

Проводится ревизия области глубокого, проекции поверхностного пахового кольца, бедренного канала. Берется на эластичную держалку семенной канатик. Вскрывается грыжевой мешок, под «контролем пальца» он выделяется выше шейки от окружающих тканей, семенного канатика, прошивается кисетным швом, иссекается. В дальнейшем производится пластика задней стенки пахового канала подшиванием поперечной фасции и нижнего края внутренней косой мышцы к подвздошно-лонному тяжу при паховых грыжах и подшиванием подвздошно-лонного тяжа к гребенчатой связке при бедренных грыжах $[2,3,5,9]$. При рецидивных и больших грыжах для пластики задней стенки пахового канала и закрытия дефектов бедренного канала мы используем сетчатый протез по методике, описанной в наших предыдущих публикациях по данной теме [6, 9, 11].

При ущемленных паховых и бедренных грыжах в случае некротических изменений ущемленного органа или самопроизвольного вправления грыжи с наличием явлений перитонита при операциях из традиционного переднего доступа возникает необходимость выполнять лапаротомию для полноценной ревизии брюшной полости и резекции некротизированного органа в должном объеме. Важно отметить, что особенности доступа по Nyhus позволяют получить достаточно большой доступ в брюшную полость (50-80 см²), конкурирующий с срединной лапаротомией. При этом успешно получается вывести ущемленный орган из ущемляющего кольца, оценить патологические изменения в самом ущемленном участке, участках проксимальнее места ущемления. Состояние относительно фиксированных прилежащих органов в случае их ущемления (слепая, сигмовидная кишки, мочевой пузырь) удается оценить достоверно. Подвижные органы (тонкая кишка, большой сальник) также удается осмотреть достоверно в пределах возможной достигаемости области ущемления. Тонкая кишка хорошо выводится в операционную рану. Некротизированный участок кишки удается успешно резецировать с соблюдением правил резекции при ущемлениях (30-40 см приводящей петли, 20-30 cм отводящей петли от зоны видимого некроза) с формированием межкишечного анастомоза. Конечно, если есть неуверенность в достоверности ревизии, либо при невозможности выполнить необходимый объем операции выполняется срединная лапаротомия. Однако в подавляющем большинстве случаев доступа по Nyhus бывает достаточно.

В нашем отделении в период 2017-2019 гг. по экстренным показаниям оперирован 51 пациент с ущемленными паховыми и бедренными грыжами, из них $39-$ с паховыми и 12 - с бедренными грыжами. Из них женщин было 17, мужчин 34, причем с бедренными грыжами были только женщины. Средний возраст боль- 
ных составил 66 лет. Большинство операций проводилось под спинальной анестезией. Эндотрахеальный наркоз, за небольшим исключением, применялся при срединных лапаротомиях.

По методикам операций получилось следующее. При ущемленных паховых грыжах со сроком ущемления от 2-10 ч без явлений перитонита и кишечной непроходимости применялся традиционный способ Бассини. Таких пациентов было 17. В пяти случаях ущемлялась тонкая кишка без некроза с уверенностью в ее жизнеспособности, операции заканчивались вправлением органа и пластикой по Бассини. В остальных случаях ущемлялась прядь большого сальника, в одном случае ущемленная прядь сальника была резецирована. Еще в трех случаях после доступа по Бассини понадобилась срединная лапаротомия, в одном из них была эластично ущемлена сигмовидная кишка с развитием толстокишечной непроходимости, в одном произошло ущемление тонкой кишки с некрозом и непроходимостью, выполнена резекция некротизированного участка с анастомозом, назоинтестинальная интубация. В одном случае ущемлялся большой сальник с некрозом, потребовалась его резекция. В одном случае была произведена операция по Постемпскому, ущемлялась тонкая кишка без некроза. В двух случаях была произведена пластика по Лихтенштейну, ущемлялся большой сальник без некроза.

При ущемленных бедренных грыжах способ Бассини применялся в трех случаях, во всех из них ущемлялся большой сальник без некроза. Еще в одном случае после доступа по Бассини понадобилась срединная лапаротомия - произведена резекция некротизированного участка тонкой кишки. Еще в одном случае при наличии явлений кишечной непроходимости сразу была выполнена срединная лапаротомия, были ущемлены слепая кишка и большой сальник без некроза, дефект бедренного канала был ушит со стороны брюшной полости.

Грыжесечение по Nyhus при ущемленных паховых грыжах выполнено у 15 пациентов. В пяти случаях ущемлялся большой сальник без некроза, в трех случаях из них потребовалась резекция ущемленного сальника. Тонкая кишка без некроза ущемлялась у трех пациентов. У четырех пациентов тонкая кишка ущемлялась с некрозом и развитием кишечной непроходимости, всем им выполнена резекция тонкой кишки с анастомозом из доступа по Nyhus. В четырех случаях для пластики задней стенки пахового канала при больших дефектах использовался сетчатый протез «Ультрапро».

Доступ и пластика по Nyhus при ущемленных бедренных грыжах использовались у 7 пациентов. У одного пациента ущемлялась тонкая кишка без некроза, у одного было рихтеровское ущемление тонкой кишки, также обошлось без резекции. У четверых пациентов было ущемление петель тонкой кишки с некрозом, у двоих из них в комбинации с ущемлением пряди большого сальника, производилась резекция некротизированных органов с наложением энтероанастомоза. После манипуляций с ущемленными органами из бедренного канала выводился грыжевой мешок, который резецировался, и производилась пластика бедренного канала по Nyhus подшиванием подвздошно-лонного тяжа к гребенчатой связке.

Один случай хотелось бы выделить особо, как достаточно редкий, и привести как клинический пример. Больная К., 85 лет, доставлена бригадой СМП с жалобами на наличие образования в паховой области справа, боли, покраснение в области образования, слабость, сухость во рту, повышение температуры тела до $38{ }^{\circ} \mathrm{C}$. Заболела остро три дня назад, когда после физической нагрузки ощутила 
А. А. Виноградов, А. Н. Плеханов, А. И. Товаршинов, В. А. Виноградов, И. А. Ольховский, Л. В. Борбоев. Опыт хирургического лечения ущемленных паховых и бедренных грыж

боли, появление образования в паховой области справа. Боли усиливались, появились покраснение, гипертермия. При поступлении состояние средней тяжести, повышенного питания - масса тела 106 кг. Живот поддут, мягкий, умеренно болезненный в пахово-подвздошной области справа. Симптомов раздражения брюшины нет. В паховой области справа определяется тугоэластичное болезненное образование около 6,0 х 8,0 см, в брюшную полость не вправляется, в области образования гиперемия кожи, инфильтрация подкожной клетчатки. С диагнозом ущемленная паховая (бедренная?) грыжа справа больная взята в операционную, под спинальной анестезией выполнен предбрюшинный доступ по Nyhus справа. Выявлено, что грыжевой мешок уходит в бедренный канал, он выведен вместе с ущемленным органом из бедренного канала в рану, вскрыт, содержит ущемленный червеобразный отросток с гангренозными изменениями, некрозом верхушки. Был расширен разрез брюшины, произведена аппендэктомия, ревизия органов, прилежащих к области ущемления, удаление грыжевого мешка, пластика дефекта бедренного канала по Nyhus, дренирование предбрюшинной клетчатки перчаточным выпускником. В дальнейшем больная получала инфузионную, антибактериальную терапию, анальгетики, физиолечение. Выписана на 9-е сутки с выздоровлением.

Bo всех случаях при доступе по Nyhus не пришлось прибегать к дополнительной срединной лапаротомии. Было одно осложнение: после операции по Nyhus при ущемлении петли тонкой кишки с некрозом, ее резекции с наложением энтероэнтероанастомоза «конец в конец» возникла несостоятельность анастомоза. На третьи сутки выполнена срединная лапаротомия, резекция анастомоза с наложением энтероэнтероанастомоза «бок в бок». В дальнейшем течение послеоперационного периода гладкое. Данное осложнение расценено как техническая погрешность при наложении анастомоза на первой операции. В остальных случаях течение послеоперационного периода у пациентов благоприятное.

Выводы:

1. Ущемленные паховые и бедренные грыжи являются одной из наиболее частых патологий в экстренных хирургических стационарах и, несмотря на современное развитие хирургии, представляют задачу, требующую повышенного внимания хирургов.

2. Метод операций по Nyhus является патогенетически обоснованным в лечении паховых и бедренных грыж. Клинически бывает сложно дифференцировать паховые и бедренные грыжи. Доступ по Nyhus является универсальным, позволяя четко дифференцировать анатомические образования пахово-бедренной области, в достаточной степени производить ревизию брюшной полости, выполнять резекцию ущемленных некротизированных органов, обходясь при этом без дополнительной срединной лапаротомии, эндотрахеального наркоза, что важно для пациентов преклонного возраста с сопутствующей тяжелой патологией.

3. Опыт операций по методу Nyhus при ущемленных паховых и бедренных грыжах в хирургическом отделении ЧУЗ «КБ «РЖД-Медицина» г. Улан-Удэ позволяет нам рекомендовать его для более широкого практического применения. 
Лuтература

1. Тимошин А. Д., Юрасов А. В., Шестаков А. А. Хирургическое лечение паховых и послеоперационных грыж передней брюшной стенки. Москва: Триада - X, 2003. 144 с. Текст: непосредственный.

2. Ненатяжная герниопластика / под редакцией В. Н. Егиева. Москва: БИНОМ, Лаборатория знаний, 2005. 144 с. Текст: непосредственный.

3. Атлас оперативной хирургии грыж / В. Н. Егиев, К. В. Лядов, П. К. Воскресенский [и др.]. Москва: Медпрактика, 2003. 228 с. Текст: непосредственный.

4. Тоскин К. Д., Жебровский В. В. Грыжи брюшной стенки. Москва: Медицина, 1990. 269 с. Текст: непосредственный.

5. Коган А. С., Веронский Г. И., Таевский А. В. Патогенетические основы хирургического лечения паховых и бедренных грыж. Иркутск: Изд-во Иркут. гос. ун-та, 1990. 171 с. Текст: непосредственный.

6. Опыт применения предбрюшинной пластики сетчатым аллотрансплантатом при паховых грыжах / И. А. Ольховский, Л. В. Борбоев, А. И. Товаршинов [и др.] // Научные труды монголо-российских хирургов. Улан-Батор, 2006. С. 185-187. Текст: непосредственный.

7. Мошкова Т. А. Новые аспекты аллопластики грыж брюшной стенки: диссертация на соискание ученой степени доктора медицинских наук. Санкт-Петербург, 2008. 301 с. Текст: непосредственный.

8. Бочкарев А. А. Выбор метода пластики передней брюшной стенки при лечении паховых грыж. Иркутск, 2009. 96 с. Текст: непосредственный.

9. Предбрюшинная пластика сетчатым полипропиленовым протезом при сложных и рецидивных грыжах по Nyhus как альтернатива методике Лихтенштейна / А. А. Виноградов, А. Н. Плеханов, А. И. Товаршинов [и др.] // Третий съезд хирургов Сибири и Дальнего Востока. Томск, 2009. С. 243. Текст: непосредственный.

10. Особенности диагностики и хирургического лечения ущемленных паховых грыж / Б. В. Сигуа, В. П. Земляной, С. В. Петров [и др.] // Эндоскопическая хирургия. 2016. 22(6). С. 14-18. Текст: непосредственный.

11. Предбрюшинная пластика сетчатым полипропиленовым протезом при паховых и бедренных грыжах / А. А. Виноградов, А. Н. Плеханов, А. И. Товаршинов [и др.] // Вестник Бурятского государственного университета. Медицина. 2010. № 12. С. 202-205. Текст: непосредственный.

Статья поступила в редакиию 09.10.2021; одобрена после рецеензирования 25.11.2021; принята к публикации 22.12.2021.

\title{
SURGICAL TREATMENT FOR INCARCERATED INGUINAL AND FEMORAL HERNIAS
}

\author{
Aleksey A. Vinogradov \\ Operating Surgeon, \\ Clinical Hospital "Russian Railways - Medicine" \\ 1 b Komsomolskaya St., Ulan-Ude 670001, Russia \\ winogradow.a@yandex.ru \\ Aleksandr N. Plekhanov \\ Dr. Sci. (Medicine), Prof., \\ Head of Intermediate Level Surgery Department, \\ Dorzhi Banzarov Buryat State University \\ 36a Oktyabrskaya St., Ulan-Ude 670000, Russia
}


Medical Director,

Clinical Hospital "Russian Railways - Medicine"

1 Komsomolskaya St., Ulan-Ude 670001, Russia

plehanov.a@mail.ru

Aleksandr I. Tovarshinov

Cand. Sci. (Medicine), A/Prof.

of Intermediate Level Surgery Department,

Dorzhi Banzarov Buryat State University

36a Oktyabrskaya St., Ulan-Ude 670000, Russia

tovarschinov.a@mail.ru

Vladimir A. Vinogradov

2nd year Student,

Dorzhi Banzarov Buryat State University

36a Oktyabrskaya St., Ulan-Ude 670000, Russia

kvendingo.mail.ru@gmail.com

Igor A. Olkhovsky

Senior Lecturer,

Dorzhi Banzarov Buryat State University

36a Oktyabrskaya St., Ulan-Ude 670000, Russia

Leonid V. Borboev

Senior Lecturer,

Dorzhi Banzarov Buryat State University

36a Oktyabrskaya St., Ulan-Ude 670000, Russia

borboev@mail.ru

Abstract. The article presents the experience of surgical treatment for incarcerated inguinal and femoral hernias in Surgery Unit of the Clinical Hospital "Russian Railways - Medicine", Ulan-Ude. Ventral hernias are one of the most common pathologies in surgery all over the world, while the results of patient treatment remain unsatisfactory, there is a high level of complications and postoperative mortality.

This is because of late referral of patients, delayed surgery, elderly and senile age of patients with a pronounced comorbidity and a subtle clinical picture. There are also problems of differential diagnosis, as well as tactical errors in choosing access, determining the scope of surgery and the method of plastics. The Nyhus method of surgery is pathogenetically substantiated for treatment of inguinal and femoral hernias, universal; it allows to clearly visualize the structure of inguinal-femoral region, examine the abdominal cavity, and resect impaired necrotized organs without additional median laparotomy, endotracheal anesthesia, which is important for patients of advanced age with concomitant severe pathology. Keywords: hernia, incarceration, the Nyhus method.

For citation

Vinogradov A. A., Plekhanov A. N., Tovarshinov A. I. et al. Surgical Treatment for Incarcerated Inguinal and Femoral Hernias. Bulletin of Buryat State University. Medicine and Pharmacy. 2021; 2: 9-15 (In Russ.).

The article was submitted 29.10.2021; approved after reviewing 25.11.2021; accepted for publication 22.12.2021. 